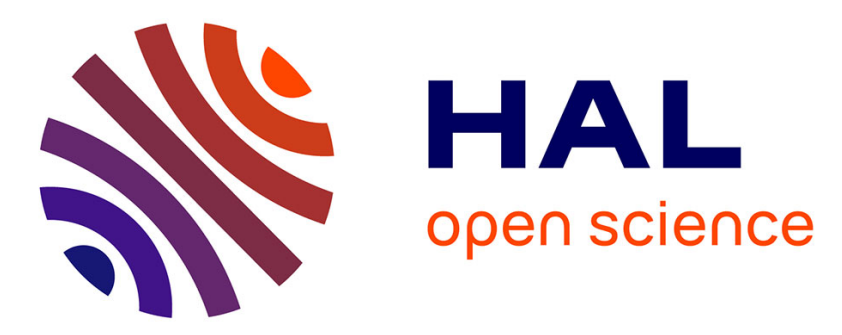

\title{
Low socioeconomic position and depression persistence: longitudinal results from the GAZEL cohort study.
} Maria Melchior, Jean-François Chastang, Annette Leclerc, Céline Ribet, Frédéric Rouillon

\section{- To cite this version:}

Maria Melchior, Jean-François Chastang, Annette Leclerc, Céline Ribet, Frédéric Rouillon. Low socioeconomic position and depression persistence: longitudinal results from the GAZEL cohort study.. Psychiatry Research, 2010, 177 (1-2), pp.92-6. 10.1016/j.psychres.2009.08.002 . inserm-00475899

\section{HAL Id: inserm-00475899 https://www.hal.inserm.fr/inserm-00475899}

Submitted on 23 Apr 2010

HAL is a multi-disciplinary open access archive for the deposit and dissemination of scientific research documents, whether they are published or not. The documents may come from teaching and research institutions in France or abroad, or from public or private research centers.
L'archive ouverte pluridisciplinaire HAL, est destinée au dépôt et à la diffusion de documents scientifiques de niveau recherche, publiés ou non, émanant des établissements d'enseignement et de recherche français ou étrangers, des laboratoires publics ou privés. 
Socioeconomic position and depression peristence.

Low socioeconomic position and depression persistence: longitudinal results from the GAZEL cohort study.

\author{
Maria Melchior $^{\mathrm{a}^{*}}$, Jean-François Chastang ${ }^{\mathrm{a}}$, Annette Leclerc ${ }^{\mathrm{a}}$, \\ Céline Ribet ${ }^{\mathrm{b}}$, Frédéric Rouillon ${ }^{\mathrm{c}}$
}

\begin{abstract}
a INSERM, U687, Villejuif, F-94807, France ; Université Paris XI, IFR69, Villejuif, F94807, France ;

${ }^{\mathrm{b}}$ CETAF-RPPC, INSERM U687, Villejuif, F-94807, France ;

' Université Paris 5 René Descartes, Paris, F-75674, France ; INSERM, U669, Paris, F75674, France ; Centre Hospitalier Sainte-Anne, Clinique des Maladies Mentales et de l'Encéphale, Paris, F-75674, France.
\end{abstract}

Word count: Abstract: 130

Text (excluding tables): 2954

Tables: 3

Running title: Socioeconomic position and depression persistence.

Corresponding author: Maria Melchior ; INSERM Unité 687 ; Hôpital Paul-Brousse 16 avenue Paul Vaillant-Couturier, Bâtiment 15/16; 94807 Villejuif Cédex, France Tél : +33 (0)177 747427 ; Fax : +33 (0)177 747403 ; maria.melchior@inserm.fr 
Socioeconomic position and depression peristence.

\begin{abstract}
Research examining the association between socioeconomic position and depression course has yielded inconsistent results. We tested the association between low socioeconomic position and 7-year depression persistence among 298 communitybased individuals with depression (subset of the Gazel cohort study based in France). Data were analyzed using Generalized Estimating Equation (GEE models). Low socioeconomic position predicted depression persistence (men: low vs. Intermediate/high income: OR: 2.52, 95\% Cl 1.28-4.95; women: low vs. Intermediate/ high occupational grade: OR: $2.25,95 \% \mathrm{Cl} 1.06-4.80)$. These associations were reduced and became statistically nonsignificant after controlling for baseline sociodemographic characteristics and stressful life events (men and women), overall health (men), and the severity of mental health difficulties (men and women). Overall, depressed individuals with low socioeconomic position appear disproportionately likely to experience multiple risk factors of long-term depression.
\end{abstract}

Keywords: depression; socioeconomic position; longitudinal study; epidemiology 
Socioeconomic position and depression peristence.

\section{Introduction}

Depression is persistent in approximately $50 \%$ of cases and identifying groups of individuals at risk of persistent depression may have clinical and policy implications ([American Psychiatric Association, 1994]). Depressed individuals who experience socioeconomic disadvantage may have poor recovery rates; however evidence on this is currently inconclusive ([Gilman et al., 2003], [Spijker et al., 2004] , [Mojtabai and Olfson, 2004], [Miech et al., 2005], [Hollon et al. 2006] , [Cohen et al., 2006] and [Cohen et al., 2009]). This is primarily due to methodological limitations of past investigations in this area. First, past studies used several different measures of socioeconomic position such as father's occupation, educational attainment ([Gilman et al., 2003], [Spijker et al., 2004] and [Miech et al., 2005]), as well as adult income level or employment status ([ Hollon et al., 2006 ] and [de Conradi and Ormel, 2008]), making it difficult to determine whether some socioeconomic factors are more relevant than others. Second, previous studies often examined the persistence of depression among patient populations ([Cohen et al., 2006], [Hollon et al., 2006], [Conradi et al., 2008], [Cohen et al., 2009]). Yet depressed individuals who seek medical treatment tend to belong to more privileged socioeconomic groups than those who do not seek treatment ([Grolleau et al, 2008]), raising the possibility that clinical samples do not allow sufficient contrast between different socioeconomic groups. Third, some studies assessed past depression using retrospective reports, which may be tainted by individuals' depressive symptoms at the time of measurement ([Gilman et al., 2003] and [Hollon et al., 2006]). In the present study, we examine the association between four distinct indicators of socioeconomic 
Socioeconomic position and depression peristence.

position and depression course in a community-based sample of depressed individuals followed prospectively for 7 years.

\section{Methods}

\subsection{Study population}

Data come from an ongoing epidemiological cohort set up in 1989 among employees of France's national gas and electricity company (GAZEL, $n=20,624 ; 25 \%$ women, $<=1 \%$ loss to follow-up since 1989) ([Goldberg et al., 2007]). In 1994, 1,108 participants were interviewed by mental health interviewers to study the determinants of depression; follow-up assessments were conducted in 1998 and 2001 by mailed questionnaire ( $91 \%$ and $88 \%$ response rate) ([Duburcq et al., 1999]). This analysis is based on participants who met diagnostic criteria for major unipolar depression in 1994 $(n=298)$.

\subsection{Measures}

Baseline socioeconomic position was measured by: a) father's occupational grade (low vs. intermediate/high), b) educational attainment (<high school degree vs. $>=$ high school degree), c) household income (<=national average of $€ 2616 /$ month vs. $>€ 2616$ / month) and d) own occupational grade (low vs. intermediate/high). Low occupational grade was defined as manual worker or clerk; other occupations constituted the intermediate/high occupational grade category ([Melchior et al., 2006]).

Mental health symptoms were ascertained using the MINI, a structured diagnostic interview validated in non-clinical populations ([Sheehan et al., 1998]). Major depression and anxiety disorders (panic disorder, agoraphobia, social phobia, obsessivecompulsive disorder, post-traumatic stress disorder, generalized anxiety disorder) were 
Socioeconomic position and depression peristence.

ascertained following DSM IV criteria ([American Psychiatric Association, 1994]). To account for the type of depression at baseline, we distinguished three groups: 1) single depressive episode, 2) recurrent depressive episode or depressive episode doubled by dysthymia, and 3) depressive episode with suicidal ideation. The group experiencing depression doubled by suicidal ideation had the highest level of depressive symptoms, health service use, and impaired functioning.

Overall, $28 \%$ of men and $48 \%$ of women in our study sample took antidepressants in the 12 months preceding assessment and respectively $13 \%$ and $13 \%$ reported consulting a psychiatrist. There was no association between pharmaceutical treatment of depression and occupational grade or income. Men and women who consulted a psychiatrist prior to the study were somewhat more likely to work in an intermediate/high grade job than in a low grade job, but this association was not statistically significant and there was no association with income. Moreover, mental health treatment was strongly associated with depression severity at baseline; among men with depression with suicidal ideation $38 \%$ took antidepressants and $22 \%$ consulted a psychiatrist, as compared with $8 \%$ and $0 \%$ among those with a single depressive episode. In women, among those with depression with suicidal ideation $52 \%$ took antidepressants and $16 \%$ consulted a psychiatrist, as compared with $33 \%$ and $14 \%$ among those with a single depressive episode. Thus, we chose not to control our analyses for mental health treatment because treatment was simultaneously unrelated to socioeconomic position and strongly associated with depression severity which our analysis does account for. 
Socioeconomic position and depression peristence.

Analyses were adjusted for baseline sociodemographic characteristics (age, marital status, social support from family and friends), stressful life events 12 months prior to the survey (divorce, hospitalization, important purchase, partner's death, partner's hospitalization, partner's unemployment) and baseline poor self-rated health.

\subsection{Statistical analysis}

We tested the hypothesis that low socioeconomic position predicts the persistence of depression during follow-up ([Spijker et al., 2001], [Solomon et al., 2004]) (that is in 1998 and/or in 2001) using Generalized Estimating Equations (GEE). First, we tested unadjusted associations; second, carrying forward indicators of socioeconomic position that were significantly associated with depression persistence, we controlled the analysis for covariates associated with depression persistence at a statistical significance level of $10 \%$. Covariates were included in the multivariate regression models by block (sociodemographic characteristics+stressful life events, overall health, mental health difficulties). All analyses were conducted separating men and women with SAS V9.

\section{Results}

In our study, $46.7 \%$ of men and $64.7 \%$ of men had persistent depression over the course of follow-up. Persistent depression was predicted by low income in men (OR: 2.52, 95\% Cl 1.28-4.95) and low occupational grade in women (OR: $2.25,95 \% \mathrm{Cl} 1.06-$ 4.80) (Table 1). In men (Table 2), the effect of low income decreased after adjusting for sociodemographic characteristics, that is age and lack of social support as well as stressful life events (OR: $1.90,95 \% \mathrm{Cl} 0.91-3.97)$ and after adjusting for overall health (OR: $2.06,95 \% \mathrm{Cl} 1.03-4.12$ ). Controlling for baseline sociodemographic characteristics 
Socioeconomic position and depression peristence.

and stressful life events, health, and mental health difficulties, that is the severity of baseline depression, the OR associated with low income decreased to 1.47 and became statistically non-significant $(95 \% \mathrm{Cl} 0.74-2.90)$. In women (Table 3), the effect of low occupational grade slightly increased after adjusting for stressful life events (OR: 2.43, $95 \% \mathrm{Cl} 1.15-5.18)$ but decreased and became statistically non-significant after adjusting for baseline mental health difficulties, that is the severity of baseline depression and comorbid anxiety (OR: $1.87,95 \% \mathrm{Cl} 0.85-4.11)$. Controlling both for stressful life events and baseline mental health difficulties, the OR associated with low occupational grade decreased to 2.01 and became statistically non-significant $(95 \% \mathrm{Cl} 0.92-4.36)$.

\section{Discussion}

\subsection{Main findings}

In a community-based cohort of depressed individuals followed for 7 years, low socioeconomic position predicted depression persistence in univariate statistical analyses. This socioeconomic disparity reflected overexposure to several risk factors of poor depression outcomes including unfavorable sociodemographic characteristics and more severe mental health difficulties, and was not statistically significant in multivariate regression models.

\subsection{Study limitations and strengths}

Our study has limitations which need to be taken into account in interpreting our findings. First, GAZEL cohort participants had stable employment and we could not study the role of unemployment or job insecurity. Second, although GAZEL includes a wide range of occupations and income levels and is characterized by strong health inequalities ([Melchior et al., 2005], [Melchior et al., 2006] and [Melchior et al., 2007]), 
Socioeconomic position and depression peristence.

we may have underestimated socioeconomic inequalities in depression persistence. Third, our analysis did not account for certain factors associated with depression course such as family history of mental illness ([Milne et al., 2009]) and age of onset of depressive illness ([Zisook et al., 2007]). However, these factors are thought to influence disease course primarily through greater symptom severity; thus by accounting for the severity of the depression episode at study baseline (single depressive episode, recurrent depressive episode/depressive episode doubled by dysthymia, or depressive episode with suicidal ideation) we probably captured most of the variability in disorder outcome that would be associated with these predictors.

Despite these limitations, our study also has several strengths which argue for the validity of our finding: 1) we systematically used four distinct indicators of socioeconomic position; 2) the sample was selected independently of mental health treatment status; 3) we used a prospective research design which limits information bias; 4) the analysis is controlled for baseline mental health difficulties.

\subsection{Socioeconomic position and depression}

The association between low socioeconomic position and depression persistence reported in our study is consistent with data from other investigations ([Gilman et al., 2003], [Mojtabai and Olfson, 2004] and [Miech et al., 2005]). In the current debate regarding the socioeconomic indicators most relevant in relation to adult depression ([Araya et al., 2003] and [Lorant et al., 2003]), our data suggest that adult circumstances (i.e. income and occupational grade) play a more important role than father's occupation in childhood. This association appears to reflect worse social and clinical characteristics at baseline and may additionally be compounded by heightened vulnerability to 
Socioeconomic position and depression peristence.

depressogenic experiences ([Bonanno et al., 2007]) and available mental health treatment ([Grolleau et al., 2008]). In particular, treatment adequacy, assessed in relation to disorder severity ([National Institute for Health and Clinical Excellence, 2007]), appears to be an important predictor of the long-term course of depression ([Koivumaa-Honkanen et al., 2008]). Unfortunately, we could not address this question as data on treatment adequacy were not collected in the GAZEL cohort; still, it will be important to test the role of adequate treatment in future research. Overall, socioeconomic inequalities in depression probably reflect both "health selection" (i.e. the influence of depression on socioeconomic attainment) and "social causation" (i.e. the influence of socioeconomic disadvantage on depression risk) ([Dohrenwend et al., 1992]). Our design did not allow us to examine this issue in detail; however, our results suggest that socioeconomic disparities in depression persistence are statistically explained by several risk factors with co-occur with low socioeconomic position. Additional longitudinal research is needed to disentangle the lifecourse processes that underlie the association between socioeconomic position and risk factors of depression persistence.

\subsection{Gender differences}

As previous researchers, we found higher rates of persistent depression in women than in men (64.7\% vs. $47.6 \%)$; this is consistent with the hypothesis that higher persistence rate contributes to women's increased lifetime risk of depression ([Mueller et al., 1999], [Bracke, 2000],[Spijker et al., 2001] and [Solomon et al., 2004]). Additionally, we observed gender differences with regard to socioeconomic predictors of depression which go along the suggestion that socioeconomic indicators have different meaning in 
Socioeconomic position and depression peristence.

women and in men ([Krieger, 1991]). For instance, in France, women are more likely than men to work in unskilled jobs (32\% as compared with $18 \%$ ) and, on average, there is a $25 \%$ earning gap ([Meurs and Pontieux 2006]) - as a result, occupational grade and income may not be directly comparable in men and in women. Our results do not allow us to conclude which socioeconomic indicators are particularly relevant in women and in men. However, when monitoring social disparities in health, researchers may need to pay special attention to measuring socioeconomic position in a gender-relevant way. Finally, in our study, the course of depression among women was associated with stressful life events and initial mental health difficulties; among men, other factors, including insufficient social support and poor overall health, played an important role. Previous research reported that, over and above clinical factors, social characteristics and physical functioning can predict depression recovery ([Spijker et al., 2004], [Conradi et al., 2008] and [Gater et al., 2008]). However, these studies combined women and men and research on gender-specific predictors of depression course is still needed.

\subsection{Conclusions}

Depressed individuals with low socioeconomic position appear to disproportionately experience persistent depression; this seems related to their high level of exposure to multiple risk factors of long-term depression. 
Socioeconomic position and depression peristence.

Acknowledgements: The authors express their thanks to GAZEL study members, EDF-GDF, especially the Service des Etudes Médicales, the Service Général de Médecine de Contrôle and the "Caisse centrale d'action sociale du personnel des industries électrique et gazière", as well the GAZEL cohort study team. Depression data in the GAZEL cohort were collected by Cimka-EVAL and the authors are grateful to Drs. Yves Charpak and Anne Duburcq for making them available for this investigation. The GAZEL cohort was funded by EDF-GDF and INSERM and received grants from the Association de la Recherche sur le Cancer, from the Fondation de France, and from the French Ministry of health (TGIR 2008). This study was supported by funding from France's Institute of Public Health Research (IReSP). 
Socioeconomic position and depression peristence.

\section{References}

American Psychiatric Association, 1994. Diagnostic and statistical manual of mental disorders (4th ed.). Washington,DC: American Psychological Association.

Araya,R., Lewis,G., Rojas,G., Fritsch,R., 2003. Education and income: which is more important for mental health? Journal of Epidemiology and Community Health, 57, 501-505.

Bonanno,G.A., Galea,S., Bucciarelli,A., Vlahov,D., 2007. What predicts psychological resilience after disaster? The role of demographics, resources, and life stress. Journal of Consulting and Clinical Psychology, 75, 671-682.

Bracke,P. , 2000. The three-year persistence of depressive symptoms in men and women. Social Science and Medicine, 51, 51-64.

Cohen,A., Gilman,S.E., Houck,P.R., Szanto,K., Reynolds,C.F., III, 2009. Socioeconomic status and anxiety as predictors of antidepressant treatment response and suicidal ideation in older adults. Social Psychiatry and Psychiatric Epidemiology, 44, 272-277.

Cohen,A., Houck,P.R., Szanto,K., Dew,M.A., Gilman,S.E., Reynolds,C.F., III, 2006. Social inequalities in response to antidepressant treatment in older adults. Archives of General Psychiatry, 63, 50-56.

Conradi,H.J., de Jonge P., Ormel,J., 2008. Prediction of the three-year course of recurrent depression in primary care patients: Different risk factors for different outcomes. Journal of Affective Disorders, 105, 267-271.

Dohrenwend,B.P., Levav,I., Shrout,P.E., Schwartz,S., Naveh,G., Link,B.G., Skodol,A.E., Stueve,A., 1992. Socioeconomic status and psychiatric disorders: the causation-selection issue. Science, 255, 946-952.

Duburcq,A., Blin,P., Charpak,Y., Blachier,C., Allicar,M.P., Bouhassira,M., Hergueta,T., Lecrubier,Y., 1999. Validation d'un entretien diagnostique structuré pour identifier les épisodes dépressifs dans un étude épidémiologique: validation interne à posteriori. Revue d'Epidémiologie et de Santé Publique, 47, 455-463.

Gater,R., Tomenson,B., Percival,C., Chaudhry,N., Waheed,W., Dunn,G., Macfarlane,G., Creed,F., 2009. Persistent depressive disorders and social stress in people of Pakistani origin and white Europeans in UK. Social Psychiatry and Psychiatric Epidemiology, 44, 198-207.

Gilman,S.E., Kawachi,I., Fitzmaurice,G.M., \& Buka,S.L., 2003. Socio-economic status, family disruption and residential stability in childhood: relation to onset, recurrence and remission of major depression. Psychological Medicine, 33, 1341-1355.

Goldberg,M., Leclerc,A., Bonenfant,S., Chastang,J.F., Schmaus,A., Kaniewski,N., Zins,M., 2007. Cohort profile: the GAZEL Cohort Study. International Journal of Epidemiology, $3632-$ 39.

Grolleau,A., Cougnard,A., Begaud,B., Verdoux,H., 2008. Congruence between diagnosis of recurrent major depressive disorder and psychotropic treatment in the general population. Acta Psychiatrica Scandinavica, 117, 20-27. 
Socioeconomic position and depression peristence.

Hollon,S.D., Shelton,R.C., Wisniewski,S., Warden,D., Biggs,M.M., Friedman,E.S., Husain,M., Kupfer,D.J., Nierenberg,A.A., Petersen,T.J., Shores-Wilson,K., Rush,A.J., 2006. Presenting characteristics of depressed outpatients as a function of recurrence: preliminary findings from the STAR ${ }^{\star}$ clinical trial. Journal of Psychiatric Research, 40, 59-69.

Koivumaa-Honkanen,H., Tuovinen,T.K., Honkalampi,K., Antikainen,R., Hintikka,J., Haatainen,K., Viinamaki,H., 2008. Mental health and well-being in a 6-year follow-up of patients with depression: Assessments of patients and clinicians. Social Psychiatry and Psychiatric Epidemiology, 43, 688-696.

Krieger,N. (1991). Women and social class: a methodological study comparing individual, household, and census measures as predictors of black/white differences in reproductive history. Journal of Epidemiology \& Community Health., 45, 35-42.

Lorant,V., Deliege,D., Eaton,W., Robert,A., Philippot,P., Ansseau,M., 2003. Socioeconomic inequalities in depression: a meta-analysis. American Journal of Epidemiology, 157, 98-112.

Melchior,M., Berkman,L.F., Kawachi,I., Krieger,N., Zins,M., Bonenfant,S., Goldberg,M., 2006. Lifelong socioeconomic trajectory and premature mortality (35-65 years) in France: findings from the GAZEL Cohort Study. Journal of Epidemiology and Community Health, 60, 937-944.

Melchior,M., Krieger,N., Kawachi,I., Berkman,L.F., Niedhammer,I., Goldberg,M., 2005. Work factors and occupational class disparities in sickness absence: findings from the GAZEL cohort study. American Journal of Public Health, 95, 1206-1212.

Melchior,M., Berkman,L.F., Niedhammer,I., Zins,M., Goldberg,M., 2007. Multiple work and family demands and mental health: a prospective study of psychiatric sickness absence in the French GAZEL study. Social Psychiatry and Psychiatric Epidemiology, 42, 573-582.

Miech,R.A., Eaton,W.W., Brennan,K., 2005. Mental health disparities across education and sex: a prospective analysis examining how they persist over the life course. Journal of Gerontology B Psychological Sciences and Social Sciences, 60 Spec No 2 93-98.

Milne, B.J., Caspi, A., Harrington, H., Poulton, R., Rutter, M., Moffitt, T.E., 2009. Predictive value of family history on severity of illness: the case for depression, anxiety, alcohol dependence, and drug dependence. Archives of General Psychiatry, 66: 738-747.

Mojtabai,R., and Olfson,M., 2004. Major depression in community-dwelling middle-aged and older adults: prevalence and 2- and 4-year follow-up symptoms. Psychological Medicine, 34, 623-634.

Meurs, D. and Pontieux, S., 2006. L'écart des salaires entre les femmes et les hommes peutil encore baisser? Econ Stat 398-399:99-129

Mueller,T.I., Leon,A.C., Keller,M.B., Solomon,D.A., Endicott,J., Coryell,W., Warshaw,M., Maser,J.D., 1999. Recurrence after recovery from major depressive disorder during 15 years of observational follow-up. American Journal of Psychiatry, 156, 1000-1006.

National Institute for Health and Clinical Excellence, 2007. Management of depression in primary and secondary care.: National Institute for Health and Clinical Excellence, NHS. 
Socioeconomic position and depression peristence.

Sheehan,D.V., Lecrubier,Y., Sheehan,K.H., Amorim,P., Janavs,J., Weiller,E., Hergueta,T., Baker,R., Dunbar,G.C., 1998. The Mini-International Neuropsychiatric Interview (M.I.N.I.): the development and validation of a structured diagnostic psychiatric interview for DSM-IV and ICD-10. Journal of Clinical Psychiatry, 59 Suppl;. 22-33.

Solomon,D.A., Leon,A.C., Endicott,J., Mueller,T.I., Coryell,W., Shea,M.T., Keller,M.B., 2004. Psychosocial impairment and recurrence of major depression. Comprehensive Psychiatry, 45, 423-430.

Spijker,J., de Graaf R., Bijl,R.V., Beekman,A.T., Ormel,J., Nolen,W.A., 2004. Determinants of persistence of major depressive episodes in the general population. Results from the Netherlands Mental Health Survey and Incidence Study (NEMESIS). Journal of Affective Disorders, 81, 231-240.

Spijker,J., Bijl,R.V., de Graaf,R., \& Nolen,W.A., 2001. Determinants of poor 1-year outcome of DSM-III-R major depression in the general population: results of the Netherlands Mental Health Survey and Incidence Study (NEMESIS). Acta Psychiatrica Scandinavica, 103, 122 130.

Zisook, S., Lesser, I., Stewart, J.W., Wisniewski, S.R., Balasubramani, G.K., Fava, M., Gilmer, W.S., Dresselhaus, T.R., Thase, M.E., Nierenberg, A.A., Trivedi, M.H., Rush, A.J. 2007. Effect of age at onset on the course of major depressive disorder. American Journal of Psychiatry, 164(10):1539-1546. 
Socioeconomic position and depression peristence.

Table 1. GAZEL cohort participants who were depressed in 1994: baseline characteristics in relation to persistent depression during follow-up: 1994-2001 (\%; OR, 95\% Cl).

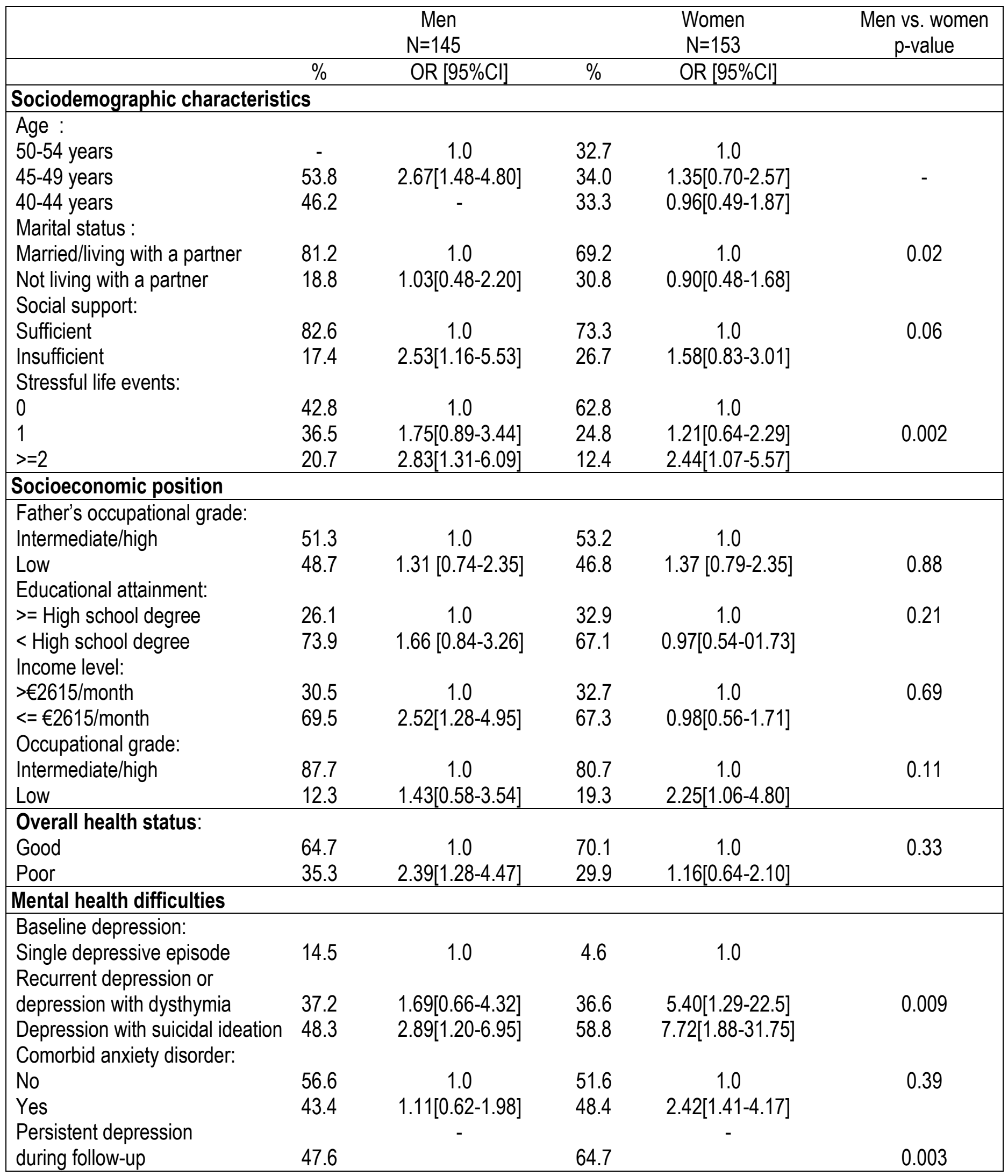


Socioeconomic position and depression peristence.

Table 2. Socioeconomic position and persistent depression in the GAZEL cohort study: men ( $n=145,1994-2001)(O R, 95 \% \mathrm{Cl})$.

\begin{tabular}{|c|c|c|c|c|c|}
\hline & Model 1 & Model 2 & Model 3 & Model 4 & Model 5 \\
\hline \multicolumn{6}{|l|}{ Income level: } \\
\hline $\begin{array}{l}>€ 2616 / \text { month } \\
<=€ 2616 / \text { month }\end{array}$ & $\begin{array}{c}1.0 \\
2.52[1.28-4.95]\end{array}$ & $\begin{array}{c}1.0 \\
1.90[0.91-3.97]\end{array}$ & $\begin{array}{c}1.0 \\
2.06[1.03-4.12]\end{array}$ & $\begin{array}{c}1.0 \\
2.38[1.22-4.64]\end{array}$ & $\begin{array}{c}1.0 \\
1.47[0.74-2.90]\end{array}$ \\
\hline \multicolumn{6}{|l|}{ Age: } \\
\hline $50-54$ years & - & 1.0 & & - & 1.0 \\
\hline $45-49$ years & & $2.86[1.49-5.49]$ & & & $3.11[1.62-6.00]$ \\
\hline \multicolumn{6}{|l|}{ Social support: } \\
\hline sufficient & - & 1.0 & & - & 1.0 \\
\hline insufficient & & $1.65[0.70-3.91]$ & & & $1.41[0.57-3.47]$ \\
\hline \multicolumn{6}{|l|}{ Stressful life events: } \\
\hline 0 & & 1.0 & & & 1.0 \\
\hline 1 & & $1.55[0.74-3.23]$ & & & $1.22[0.57-2.62]$ \\
\hline$>=2$ & & $2.45[1.02-5.88]$ & & & $2.96[1.21-7.24]$ \\
\hline \multicolumn{6}{|l|}{ Overall health status: } \\
\hline good & & & 1.0 & & 1.0 \\
\hline \multirow{2}{*}{\multicolumn{6}{|c|}{ Baseline depression: }} \\
\hline & & & & & \\
\hline single depressive episode & & & & 1.0 & 1.0 \\
\hline recurrent depression or depression with dysthymia & - & - & & $1.30[0.50-3.37]$ & $1.87[0.70-5.01]$ \\
\hline depression with suicidal ideation & & & & $2.45[1.00-6.03]$ & $3.09[1.23-7.77]$ \\
\hline
\end{tabular}


Socioeconomic position and depression peristence.

Table 3. Socioeconomic position and persistent depression in the GAZEL cohort study: women ( $n=153,1994-2001)$ (OR, 95\% Cl).

\begin{tabular}{|lcccc|}
\hline & Model 1 & Model 2 & Model 3 & Model 4 \\
\hline Occupational grade: & & & & \\
intermediate/high & 1.0 & 1.0 & 1.0 & 1.0 \\
low & $2.25[1.06-4.80]$ & $2.43[1.15-5.18]$ & $1.87[0.85-4.11]$ & $2.01[0.92-4.36]$ \\
Stressful life events: & & & & \\
0 & & 1.0 & & 1.0 \\
1 & & $2.50[1.09-5.20]$ & & $1.00[0.50-2.01]$ \\
$>=2$ & - & & & $2.17[0.93-5.09]$ \\
Baseline depression: & & & $3.83[0.89-16.44]$ & $3.48[0.81-14.88]$ \\
single depressive episode & & & $4.72[1.08-20.56]$ & $4.14[0.94-18.25]$ \\
recurrent depression or depression with dysthymia & - & & & 1.0 \\
depression with suicidal ideation & & & $1.84[1.01-3.34]$ & $1.85[1.01-3.38]$ \\
Comorbid anxiety disorder: & & & &
\end{tabular}

